\title{
Detectors and Focal Plane Modules for Weather Satellites
}

\author{
A.I. D’Souza, E. Robinson, S. Masterjohn, P. Ely, V. Khalap \\ DRS Sensors \& Targeting Systems, 10600 Valley View St., Cypress, CA 90630 \\ S. Babu \\ NASA Goddard Space Flight Center, 8800 Greenbelt Rd, Greenbelt, MD 20771 \\ D. S. Smith \\ Harris Semiconductor, 1919 W. Cook Rd., Ft. Wayne, IN 46818
}

\begin{abstract}
Weather satellite instruments require detectors with a variety of wavelengths ranging from the visible to VLWIR. One of the remote sensing applications is the geostationary GOES-ABI imager covering wavelengths from the 450 to $490 \mathrm{~nm}$ band through the 13.0 to $13.6 \mu \mathrm{m}$ band. There are a total of 16 spectral bands covered. The Cross-track infrared Sounder (CrIS) is a Polar Orbiting interferometric sensor that measures earth radiances at high spectral resolution, using the data to provide pressure, temperature and moisture profiles of the atmosphere. The pressure, temperature and moisture sounding data are used in weather prediction models that track storms, predict levels of precipitation etc. The CrIS instrument contains SWIR $\left(\lambda_{c} \sim 5 \mu \mathrm{m}\right.$ at $\left.98 \mathrm{~K}\right)$, MWIR $\left(\lambda_{c} \sim 9 \mu \mathrm{m}\right.$ at $\left.98 \mathrm{~K}\right)$ and LWIRs $\left(\lambda_{c} \sim 15.5 \mu \mathrm{m}\right.$ at $\left.81 \mathrm{~K}\right)$ bands in three Focal Plane Array Assemblies (FPAAs).

GOES-ABI contains three focal plane modules (FPMs), (i) a visible-near infrared module consisting of three visible and three near infrared channels, (ii) a MWIR module comprised of five channels from $3.9 \mu \mathrm{m}$ to $8.6 \mu \mathrm{m}$ and (iii) a $9.6 \mu \mathrm{m}$ to $13.3 \mu \mathrm{m}$, five-channel LWIR module. The VNIR FPM operates at $205 \mathrm{~K}$, and the MWIR and LWIR FPMs operate at 60 $\mathrm{K}$. Each spectral channel has a redundant array built into a single detector chip. Switching is thus permitted from the primary selected array in each channel to the redundant array, given any degradation in performance of the primary array during the course of the mission. Silicon p-i-n detectors are used for the $0.47 \mu \mathrm{m}$ to $0.86 \mu \mathrm{m}$ channels. The thirteen channels above $1 \mu \mathrm{m}$ are fabricated in various compositions of $\mathrm{Hg}_{1-\mathrm{x}} \mathrm{Cd}_{\mathrm{x}} \mathrm{Te}$, and in this particular case using two different detector architectures. The $1.38 \mu \mathrm{m}$ to $9.61 \mu \mathrm{m}$ channels are all fabricated in $\mathrm{Hg}_{1-\mathrm{x}} \mathrm{Cd}_{\mathrm{x}} \mathrm{Te}$ grown by Liquid Phase Epitaxy (LPE) using the HDVIP detector architecture. Molecular beam epitaxy (MBE)-grown $\mathrm{Hg}_{1-\mathrm{x}} \mathrm{Cd}_{\mathrm{x}} \mathrm{Te}$ material are used for the LWIR $10.35 \mu \mathrm{m}$ to $13.3 \mu \mathrm{m}$ channels fabricated in Double layer planar heterostructure (DLPH) detectors. This is the same architecture used for the CrIS detectors

CrIS detectors are $850 \mu \mathrm{m}$ diameter detectors with each FPAA consisting of nine photovoltaic detectors arranged in a $3 \mathrm{x}$ 3 pattern. Each detector has an accompanying cold preamplifier. SWIR and MWIR FPAAs operate at $98 \mathrm{~K}$ and the LWIR FPAA at $81 \mathrm{~K}$, permitting the use of passive radiators to cool the detectors. D* requirements at peak wavelength are $\geq 5.0 \mathrm{E}+10$ Jones for LWIR, $\geq 9.3 \mathrm{E}+10$ Jones for MWIR and $\geq 3.0 \mathrm{E}+11$ Jones for SWIR. All FP AAs exceeded the $D^{*}$ requirements. Measured mean values for the nine photodiodes in each of the LWIR, MWIR and SWIR FPAAs are $\mathrm{D}^{*}=5.3 \times 10^{10} \mathrm{~cm}-\mathrm{Hz}^{1 / 2} / \mathrm{W}$ at $14.0 \mu \mathrm{m}, 1.0 \times 10^{11} \mathrm{~cm}-\mathrm{Hz}^{1 / 2} / \mathrm{W}$ at $8.0 \mu \mathrm{m}$ and $3.1 \times 10^{11} \mathrm{~cm}-\mathrm{Hz}^{1 / 2} / \mathrm{W}$ at $4.64 \mu \mathrm{m}$.
\end{abstract}

\subsection{Introduction}

GOES-ABI is the next generation of geostationary weather satellite imager instruments. The ABI instrument utilizes detector arrays hybridized to ROICs with multiple FPAs assembled on a FPM. ABI has three Focal Plane modules (FPMs) cooled with an active cryo-cooler. DRS is contracted to design, manufacture, test, and deliver FPMs to Harris, the ABI instrument prime contractor integrator. The three focal plane modules (FPMs), (i) a visible-near infrared module consisting of three visible and three near infrared channels, (ii) a MWIR module comprised of five channels from $3.9 \mu \mathrm{m}$ to $8.6 \mu \mathrm{m}$ and (iii) a $9.6 \mu \mathrm{m}$ to $13.3 \mu \mathrm{m}$, five-channel LWIR module. The detectors were manufactured in silicon for the three sub-1 $\mu \mathrm{m}$ channels. The thirteen channels above $1 \mu \mathrm{m}$ were fabricated in various compositions of $\operatorname{Hg}_{1-\mathrm{x}} \mathrm{Cd}_{\mathrm{x}} \mathrm{Te}$, and in this particular case using two different detector architectures. The $1.38 \mu \mathrm{m}$ to $9.61 \mu \mathrm{m}$ channels were all fabricated in 
$\mathrm{Hg}_{1-\mathrm{x}} \mathrm{Cd}_{\mathrm{x}} \mathrm{Te}$ using the HDVIP ${ }^{1,2}$ detector architecture. Double layer planar heterostructure ${ }^{3-9}$ (DLPH) detectors fabricated in molecular beam epitaxy (MBE)-grown $\mathrm{Hg}_{1-\mathrm{x}} \mathrm{Cd}_{\mathrm{x}} \mathrm{Te}$ material were used for the LWIR $10.35 \mu \mathrm{m}$ to $13.3 \mu \mathrm{m}$ channels. Silicon p-i-n detectors were used for the $0.47 \mu \mathrm{m}$ to $0.86 \mu \mathrm{m}$ channels.

The CrIS instrument is a three-spectral-band Fourier Transform infrared (FTIR) spectrometer designed to measure vertical atmospheric profiles of temperature, moisture, and pressure. CrIS employs $850-\mu \mathrm{m}$-diameter DLPH Lateral Collection Dectector architecture photovoltaic detectors without ROICs, but each detector is coupled to a separate cold JFET preamplifier and associated passive electronic elements. The detector/amplifier chain requires high performance and linear photoresponse. Photovoltaic mercury cadmium telluride ( $\mathrm{HgCdTe})$ detectors coupled with the right amplifier provide both the near-theoretical background-limited infrared performance (BLIP) and the required linear response and are therefore desirable for interferometric infrared sounders such as CrIS. The CrIS instrument uses Focal Plane Array Assemblies (FPAAs) for the three spectral bands: SWIR, MWIR, and LWIR. Each FPAA comprises nine separate detectors arranged in a $3 \times 3$ pattern

This paper outlines the data collected from both GOES-ABI FPAs and CrIS detectors and all three FPAAs (SWIR, MWIR \& LWIR). The focus of this paper, however, is the LWIR FPAA, the most stressing of the three colors. Each assembly is tested separately in the CrIS dedicated nitrogen heli-tran dewar.

\subsection{Requirements}

\subsection{GOES-ABI}

The array formats and basic FPA performance parameters are listed in table I for the 16 spectral channels on ABI. Where possible, to save cost, some channels use a common FPA with a different integration capacitor setting or AR coating. Detector element sizes of the arrays vary depending on each spectral channel's ground sample distance (GSD) requirements. In all cases column redundancy was employed to maintain $100 \%$ row operability on all channels. To minimize the effects of clock coupled noise, the master clock frequencies were chosen to be multiples of each other such that all the FPAs are running synchronously. All FPA channels have a single analog output, with the exception of the $064 \mathrm{ch}$ which has 5 parallel outputs due to the higher resolution and data rate requirements.

Table I: GOES FPA Design Parameters and Performance Characteristic

\begin{tabular}{|c|c|c|c|c|c|c|c|c|c|c|c|c|c|c|c|}
\hline \multirow[t]{3}{*}{$\begin{array}{l}\bar{\Phi} \\
\stackrel{5}{ \pm} \\
\text { ঠ }\end{array}$} & $\begin{array}{c}\text { Number } \\
\text { of } \\
\text { Elements } \\
\text { N/S }\end{array}$ & $\begin{array}{c}\text { \# of } \\
\text { Redundant } \\
\text { Columns } \\
\text { per Side }\end{array}$ & 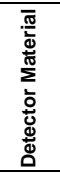 & \multicolumn{2}{|c|}{$\begin{array}{c}\text { Detector } \\
\text { Element } \\
\text { Physical Size }\end{array}$} & $\begin{array}{c}\text { Cut Off } \\
\text { Wavelength }\end{array}$ & QE (Min) & $\begin{array}{c}\text { Nom+Bkg } \\
\text { Flux }\end{array}$ & $\begin{array}{c}\text { NEI @ } \\
\text { Nom+Bkg } \\
\text { Flux }\end{array}$ & $T$ in $K$ & $\mathbf{R}_{\text {zero }}($ Min) & $\begin{array}{c}\text { Idark }\left(\mathrm{V}_{\mathrm{d}}=\right. \\
\text { Max Bias }) \\
\text { Min }\end{array}$ & $\begin{array}{l}\text { ROIC } \\
\text { Conv } \\
\text { Gain }\end{array}$ & $\begin{array}{l}\text { Integ. } \\
\text { Time }\end{array}$ & $\begin{array}{c}\text { \# of } \\
\text { Outputs }\end{array}$ \\
\hline & elements & columns & none & \multicolumn{2}{|c|}{$\mathrm{um}$} & microns & none & $\mathrm{ph} / \mathrm{cm} 2 / \mathrm{sec}$ & $\mathrm{ph} / \mathrm{cm} 2 / \mathrm{sec}$ & Kelvin & ohm cm ${ }^{2}$ & Amps & $\mathrm{V} / \mathrm{e}-$ & usec & $\#$ \\
\hline & & & & $\mathrm{N} / \mathrm{S}$ Value & E/W Value & Cut Off Value & & & & & & & & & \\
\hline 047 & 676 & 3 & $\mathrm{Si}$ & 24.0 & 24.0 & 0.90 & 0.60 & $1.54 \mathrm{E}+14$ & $2.43 \mathrm{E}+11$ & 205 & $2.00 \mathrm{E}+06$ & $5.09 \mathrm{E}-14$ & 1.89E-06 & 873 & 1 \\
\hline 086 & 676 & 3 & $\mathrm{Si}$ & 24.0 & 24.0 & 0.90 & 0.50 & $1.41 \mathrm{E}+14$ & $2.32 \mathrm{E}+11$ & 205 & $2.00 \mathrm{E}+06$ & $5.09 \mathrm{E}-14$ & $2.04 \mathrm{E}-06$ & 873 & 1 \\
\hline 138 & 372 & 6 & $\mathrm{MCT}$ & 44.0 & 54.0 & 2.45 & 0.60 & $3.12 \mathrm{E}+13$ & $4.57 \mathrm{E}+10$ & 205 & $6.00 \mathrm{E}+05$ & $1.73 \mathrm{E}-13$ & $1.12 \mathrm{E}-06$ & 1774 & 1 \\
\hline 161 & 676 & 6 & MCT & 24.0 & 24.0 & 2.45 & 0.60 & $9.55 \mathrm{E}+13$ & $1.77 \mathrm{E}+11$ & 205 & $6.00 \mathrm{E}+05$ & $4.18 \mathrm{E}-14$ & $2.97 \mathrm{E}-06$ & 871 & 1 \\
\hline 225 & 372 & 6 & MCT & 44.0 & 54.0 & 2.45 & 0.60 & $2.02 \mathrm{E}+13$ & $3.10 \mathrm{E}+10$ & 205 & $6.00 \mathrm{E}+05$ & \begin{tabular}{|l|}
$1.73 \mathrm{E}-13$ \\
\end{tabular} & $1.74 \mathrm{E}-06$ & 1774 & 1 \\
\hline 064 LL & 1460 & 3 & $\mathrm{Si}$ & 11.0 & 13.0 & 0.90 & 0.70 & $2.46 \mathrm{E}+13$ & $3.08 \mathrm{E}+11$ & 205 & $2.00 \mathrm{E}+06$ & \begin{tabular}{|c|}
$1.26 \mathrm{E}-14$ \\
\end{tabular} & $3.55 \mathrm{E}-06$ & 422 & 5 \\
\hline 390 & 332 & 6 & MCT & 50.0 & 54.0 & 5.20 & 0.60 & $1.51 \mathrm{E}+13$ & $2.76 E+10$ & 60 & $2.00 \mathrm{E}+08$ & $4.33 \mathrm{E}-16$ & $2.46 \mathrm{E}-07$ & 1766 & 1 \\
\hline 618 & 332 & 6 & MCT & 50.0 & 54.0 & 9.50 & 0.60 & $6.92 \mathrm{E}+14$ & $1.91 \mathrm{E}+11$ & 60 & $1.00 \mathrm{E}+04$ & $8.65 \mathrm{E}-12$ & $5.60 \mathrm{E}-08$ & 1766 & 1 \\
\hline 695 & 332 & 6 & MCT & 50.0 & 54.0 & 9.50 & 0.60 & $4.52 \mathrm{E}+14$ & $1.64 \mathrm{E}+11$ & 60 & $1.00 \mathrm{E}+04$ & $8.65 \mathrm{E}-12$ & $8.09 \mathrm{E}-08$ & 1766 & 1 \\
\hline 734 & 332 & 6 & MCT & 50.0 & 54.0 & 9.50 & 0.60 & $2.79 \mathrm{E}+14$ & $1.50 \mathrm{E}+11$ & 60 & $1.00 \mathrm{E}+04$ & $8.65 \mathrm{E}-12$ & \begin{tabular}{l|}
$1.04 \mathrm{E}-07$ \\
\end{tabular} & 1766 & 1 \\
\hline 850 & 332 & 6 & MCT & 50.0 & 54.0 & 9.50 & 0.60 & $6.92 \mathrm{E}+14$ & $2.19 \mathrm{E}+11$ & 60 & $1.00 \mathrm{E}+04$ & $8.65 \mathrm{E}-12$ & $3.35 \mathrm{E}-08$ & 1766 & 1 \\
\hline 1120 & 408 & 6 & MCT & 40.0 & 36.0 & 12.80 & 0.55 & $1.81 \mathrm{E}+15$ & $5.81 \mathrm{E}+11$ & 60 & $2.40 \mathrm{E}+02$ & $1.92 \mathrm{E}-10$ & $3.55 \mathrm{E}-08$ & 1772 & 1 \\
\hline 1230 & 408 & 6 & MCT & 40.0 & 36.0 & 14.10 & 0.55 & $1.83 \mathrm{E}+15$ & $6.45 \mathrm{E}+11$ & 60 & $4.92 \mathrm{E}+01$ & \begin{tabular}{|c|}
$1.48 \mathrm{E}-09$ \\
\end{tabular} & $2.47 \mathrm{E}-08$ & 1772 & 1 \\
\hline 1330 & 408 & 6 & MCT & 40.0 & 36.0 & 15.00 & 0.55 & $9.91 \mathrm{E}+14$ & $9.12 \mathrm{E}+11$ & 60 & $2.00 \mathrm{E}+01$ & \begin{tabular}{|c|}
$3.65 \mathrm{E}-09$ \\
\end{tabular} & $2.89 \mathrm{E}-08$ & 1772 & 1 \\
\hline
\end{tabular}

Each FPA channel has a corresponding narrow band filter to define the channel spectral characteristics. The channel designations are the center wavelength of each spectral channel. The spectral transmission, bandpass, shape of the spectral band edges and out of band rejection of the filters are all strictly specified to the filter vendors. The cutoff 
wavelength were all chosen to be long enough not to impinge on the spectral filter cutoff, insuring high quantum efficiency over the entire spectral band.

\subsection{CrIS}

The CrIS spectral bands and operating temperatures of interest determine the $\mathrm{HgCdTe}$ material growth parameters. Table II is a listing of the baseline material parameters and the flowdown detector performance required at the operating temperature for each wavelength detector fabricated in that material.

Table II. CrIS detector performance requirements

\begin{tabular}{|c|c|c|c|c|}
\hline Parameter & Units & SWIR & MWIR & LWIR \\
\hline Spectral Band & $\mu \mathrm{m}$ & $3.92-4.64$ & $5.71-8.26$ & $9.13-15.38$ \\
\hline Operating T & $\mathrm{K}$ & 98 & 98 & 81 \\
\hline Detector architecture & & p-on-n & p-on-n & p-on-n \\
& & DLPH & DLPH & DLPH \\
\hline Cutoff wavelength $\lambda_{\mathrm{c}}$ & $\mu \mathrm{m}$ & $>4.96$ & $>8.92$ & $>15.3$ \\
\hline Peak wavelength $\lambda_{\mathrm{p}}$ & $\mu \mathrm{m}$ & 4.64 & 8.26 & 14.01 \\
\hline $\mathrm{R}_{\mathrm{o}}$ & $\Omega$ & $>1.0 \times 10^{9}$ & $>1.4 \times 10^{4}$ & $>1.0 \times 10^{2}$ \\
\hline $\mathrm{I}_{\mathrm{d}} @$ & $\mathrm{Mmps}$ & $<1.0 \times 10^{-9}$ & $<6.0 \times 10^{-7}$ & $<7.0 \times 10^{-5}$ \\
$\mathrm{~V}_{\mathrm{d}}=-0.1 \mathrm{~V}$ & & & & $>0.6$ \\
\hline AR-coated QE & & $>0.75$ & $>0.72$ & $865 \pm 20$ \\
\hline Detector diameter & $\mu \mathrm{m}$ & $890 \pm 30$ & $870 \pm 20$ & \\
\hline
\end{tabular}

\subsection{Detector Technology}

ABI utilizes three detector technologies: Si pin detectors for the visible bands, HDVIP® MCT detectors for the 138 961 bands and DLPH MBE MCT detectors for the 1035-1330 bands (see table 1). The CrIS program uses the DLPH MBE MCT detectors. Cross sections of the different detector architectures are displayed in figure 1. Each detector technology has its advantages and limitations. The detector technology best suited for each spectral channel was chosen from a performance, cost and reliability standpoint.

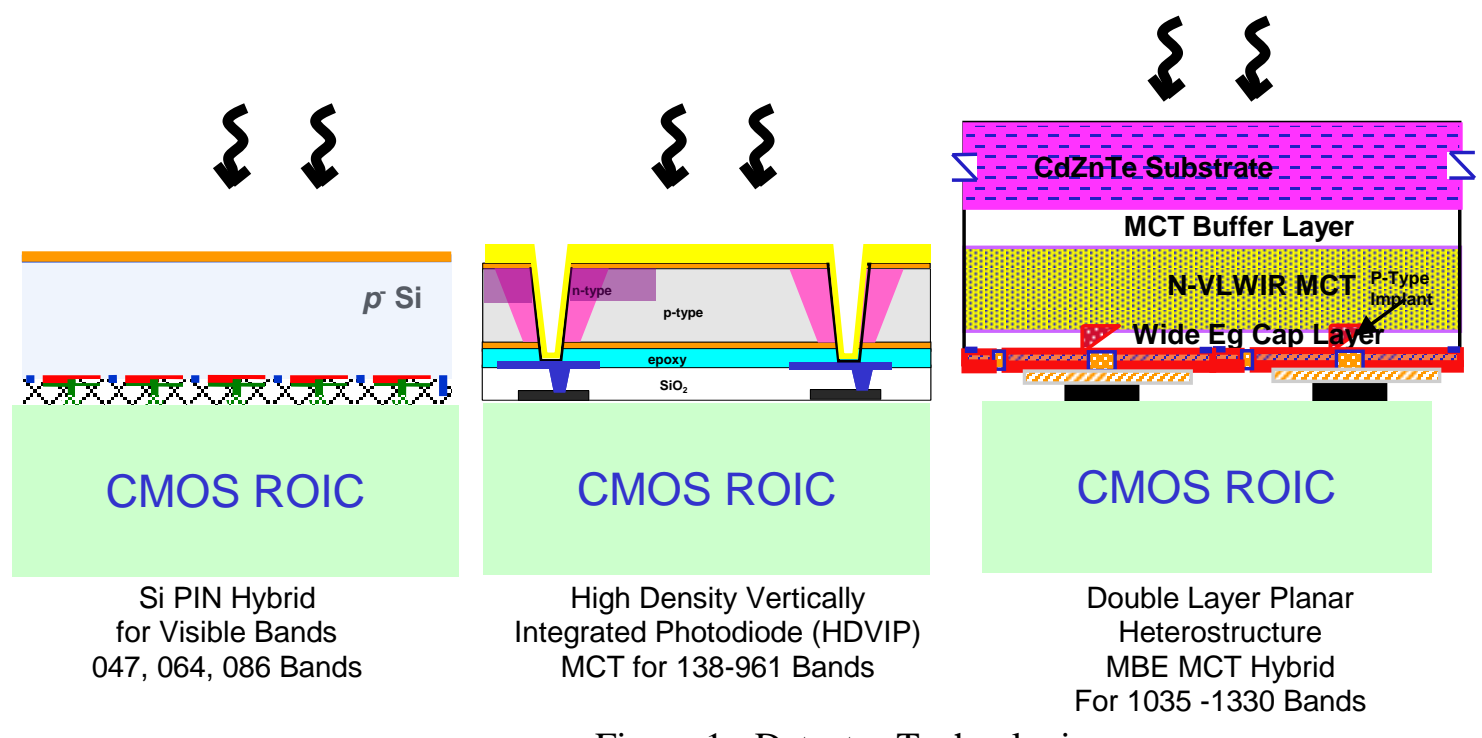

Figure 1: Detector Technologies

\subsection{Visible pin Detector}


The Si visible pin detector manufactured by DRS Sensors \& Targeting Systems is used for the 047, 064 and 086 channels. The array consists of a Si pin detector mated to a CMOS ROIC using indium bump hybridization. Three array formats $676 \times 3,1460 \times 3$ and $676 \times 3$ for the 047,064 and 086 channels respectively share a common Si Substrate. The arrays are spaced out adequately to allow discrete bandpass filters to be mounted above each array and allow room for blackened baffles to be located in between each array channel for stray light control. The resultant detector array is a $\mathrm{Si}$ chip that has overall dimensions $\sim 14 \mathrm{~mm} \times 18 \mathrm{~mm}$. The detector elements are $24 \times 24 \mu \mathrm{m}$ for the 047 and 086 channels, while the $064 \mathrm{ch}$ has $11 \mathrm{x} 13 \mu \mathrm{m}$ detectors. The detector thickness is thinned to $22 \mu \mathrm{m}$ to maximize the $047 \mathrm{ch}$ MTF, since $470 \mathrm{~nm}$ photons are all absorbed near the detector back surface, while still providing good QE for the 064 and $086 \mathrm{ch}$ whose photons have deeper penetration depth into the Si. The detectors are fully depleted, providing high QE and near theoretical MTF performance in all three color bands. A multi-layer broadband AR coating was used to maintain high QE and low reflectance across all three spectral bands.

The CMOS ROIC for each channel is independent and has logic to select the best detector from 1 of 3 columns. The best performing detector for each row is connected through a FET to each row's unit cell circuitry and read out through a single analog output for the 047 and 086 channels, while the high resolution 064 ch has 5 parallel outputs due to the larger format and higher data rate. Our design architecture provides superior crosstalk, blooming and MTF performance.

\subsection{HDVIP® SWIR - LWIR MCT Detectors}

The SWIR detectors $(1.38 \mu \mathrm{m}, 1.61 \mu \mathrm{m}$ and $2.25 \mu \mathrm{m}$ channels), all the MWIR band channels $(3.90 \mu \mathrm{m}, 6.18 \mu \mathrm{m}, 6,95$ $\mu \mathrm{m}, 7.34 \mu \mathrm{m}$ and $8.50 \mu \mathrm{m}$ ) and the $9.61 \mu \mathrm{m}$ channel in the LWIR band utilize DRS' HDVIP ${ }^{\circledR}$ MCT detectors. ${ }^{1,2}$ These detectors implement a cylindrical vertical photodiode architecture with a thru hole via to make connection to the ROIC below. The detector is a thinned, front side illuminated architecture that has high QE and fill factor and, low dark current. Thickness for the SWIR arrays is $\sim 6 \mu \mathrm{m}$ and $\sim 10 \mu \mathrm{m}$ for the MWIR and LWIR arrays. The inclusion of a surface implant for the larger pitch designs improves MTF and crosstalk and was implemented in the flight design.

\subsection{MBE DLPH VLWIR Detectors}

The baseline detector architecture for the 1035 to 1330 channels is a p-on-n double layer planar heterostructure (DLPH) diode fabricated by Teledyne Imaging Systems. A DLPH device cross section schematic is shown in Figure 1. Benefits of the $\mathrm{DLPH}^{2-9}$ architecture, include a reduction in surface generation-recombination and tunneling currents, and an increase in total dose radiation hardness, both of which are essential detector attributes for remote sensing applications. Those benefits are realized by incorporating a buried narrow-bandgap active layer in the DLPH architecture. The baseline CrIS detector architecture is also p-on-n double layer planar heterostructure (DLPH) lateral collection diode. MBE is used to grow the appropriate bandgap n-type $\mathrm{Hg}_{1-\mathrm{x}} \mathrm{Cd}_{\mathrm{x}} \mathrm{Te}$ on lattice matched CdZnTe. Wafer material is grown with wider bandgap cap layers, the subsequent detector architecture translating into the DLPH architecture. $850 \mu \mathrm{m}$ diameter detectors are manufactured using the lateral collection diode (LCD) architecture ${ }^{10}$ to reduce the probability of a performance degrading defect ${ }^{11}$ intersecting the detector $\mathrm{p} / \mathrm{n}$ junction.

\subsection{Module Design}

\subsection{GOES-ABI Focal Plane Module (FPM)}

DRS' design approach for ABI was to design each of the three module types with similar construction. An exploded view of the MWIR Module in Figure 2 shows the critical pieces which include an FPM base assembly, modular FPA mounting blocks attached to the base with screws to allow for FPA rework/replacement if necessary, an integrated constantan flex cable assembly consisting of two adhesively bonded flex cables per redundant side of the module, decoupling filter capacitors on the rigid end of the flex for bias supply filtering, temp sensors for temperature monitoring, 5 FPAs each adhesively bonded to its own mounting block (for the MWIR module shown), a 2 piece filter frame baffle assembly 
containing 5 discrete narrowband filters, and a cover shield to protect the module during handling and instrument integration.

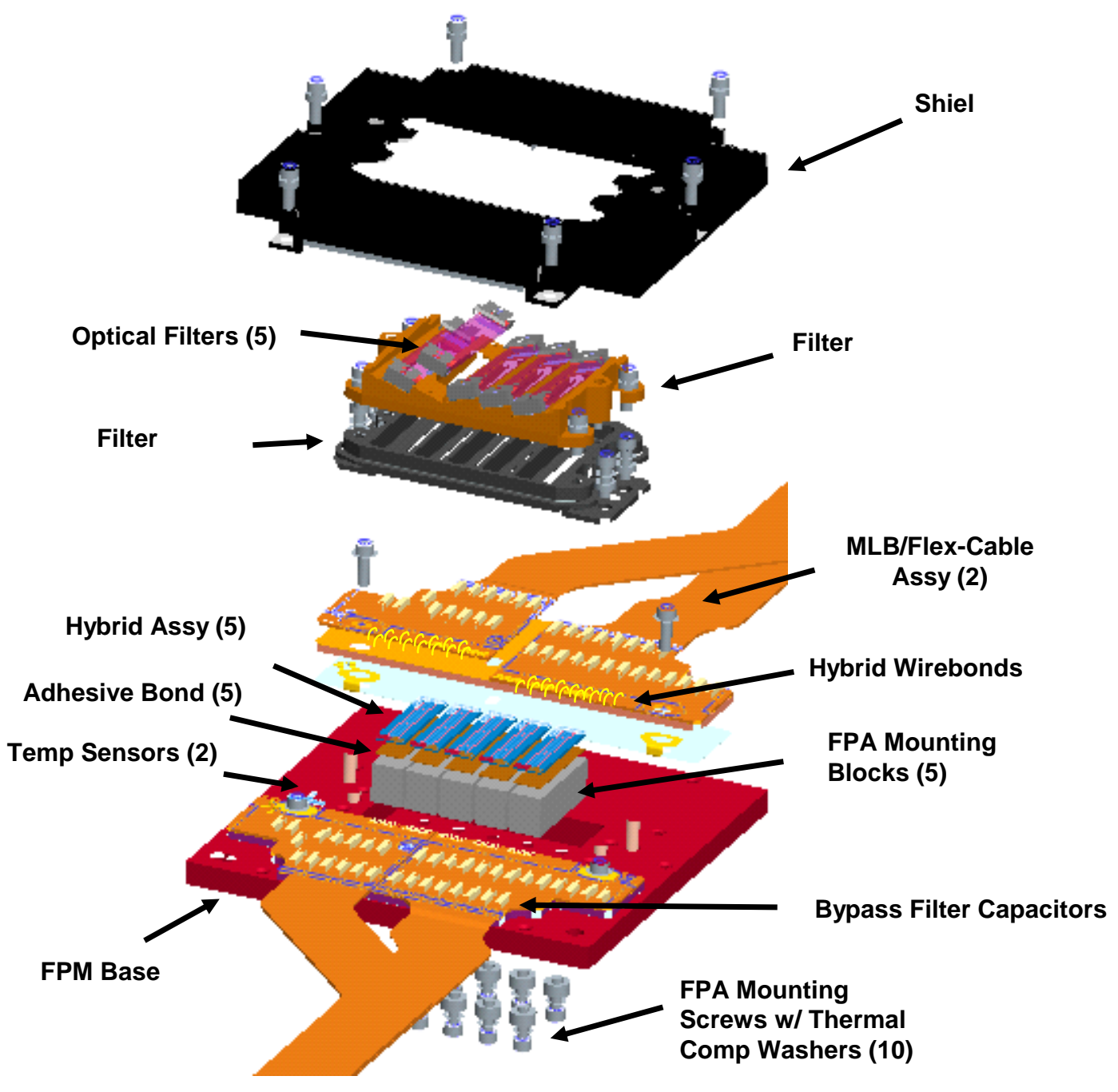

Figure 2. Exploded View of ABI MWIR FPM

The MWIR and LWIR modules have 5 spectral channels for each module and the VNIR module has 6 spectral channels. The linear arrays within each module are precision aligned parallel to one another, with all three modules bore sighted to view the same ground swath through the same telescope and scan mirror assembly. Within the optical beam path of the instrument, each module color band is separated by dichroic beam splitters.

The module construction involves attachment of the mounting plates to the base assembly with screws. The FPAs are then precision mounted to the mounting plates using an adhesive bond relative to a datum on the module. There are FPA alignment tolerances for $\mathrm{x}, \mathrm{y}$ and $\mathrm{z}$ placement as well as rotational and tilt alignment tolerances. The constantan flex cables with filter capacitors installed are then precision aligned to the base assembly and attached with screws. The FPAs are wirebonded to the flex cable and $100 \%$ pull tested to verify bond integrity. Temperature sensors are also mounted to the base assembly and electrically connected via the flex cable. Baseline testing is performed to verify all FPAs are operating as expected. Figure 3 shows the VNIR, MWIR and LWIR FM1 modules at various steps in the module assembly process. 


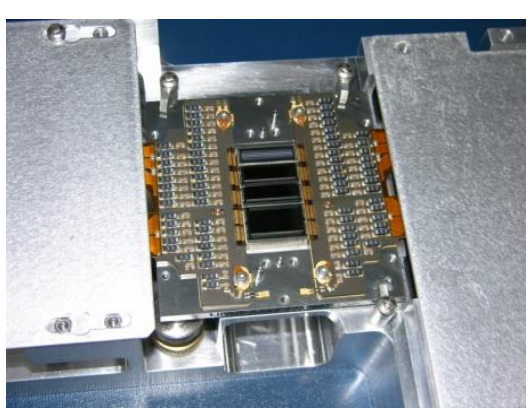

LWIR FM1 Post Wirebond

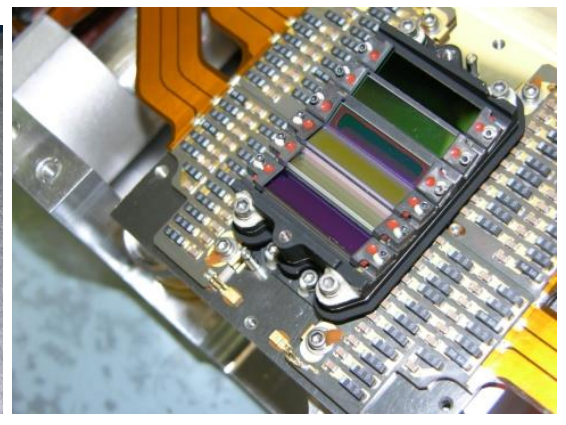

VNIR FM1 Post Filter Installation

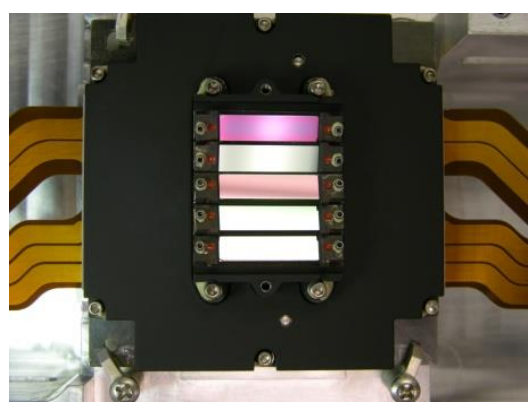

Completed MWIR FM1

Figure 3: ABI FM1 VNIR, MWIR and LWIR Modules at various stages of Integration

\subsection{CrIS Focal Plane Array Assembly (FPAA)}

The Flight configuration for the CrIS Detector Preamplifier Module (DPM) consists of three spectrally separate (SWIR, MWIR and LWIR) FPAAs, three signal flex cable assemblies, a warm signal flex cable, vacuum bulk head assembly, and the warm electronics circuit card assemblies (CCAs) as shown in figure 4. The photodiodes are coupled to a differential J-FET buffered, resistive feedback, transimpedance amplifier (RTIA). The RTIA provides the necessary gain for the circuit, and the J-FET differential buffers provide low noise, current to voltage conversion at constant output impedance. Each FPAA contains a 3 × 3 array of nine $850 \mu \mathrm{m}$ diameter photovoltaic detectors, each driving its own RTIA, with their associated cold electronics, detector optics assembly, and two flex cable assemblies with interface connectors. The FPAAs (detector arrays, detector optics assemblies, JFET buffer and feedback resistor portions of the transimpedance preamplifier, and flex cable assemblies) are cooled by the detector cooler module in their final configuration. The cryogenic portions of the DPM (FPAAs, and Signal Flex Cable Assemblies) mate to the ambient temperature portions of the DPM (warm signal flex cable assembly and the ambient temperature portions of the transimpedance amplifier, mounted within the CCAs) through the vacuum bulk head assembly mounted on the detector cooler assembly housing. The FPAA assembly is connected to the warm electronics via a constantan cable and vacuum feedthru hermetic connector. Each FPAA has its own Circuit Card Assembly (CCA) that contains a warm amplifier and the second stage $300 \mathrm{~Hz}$ high pass filter. One warm cable assembly provides the FPAA signals for all three bands. The CCA also provides the biases for the cold JFET pair on the cold electronics Ceramic Multilayer Board (CMLB).

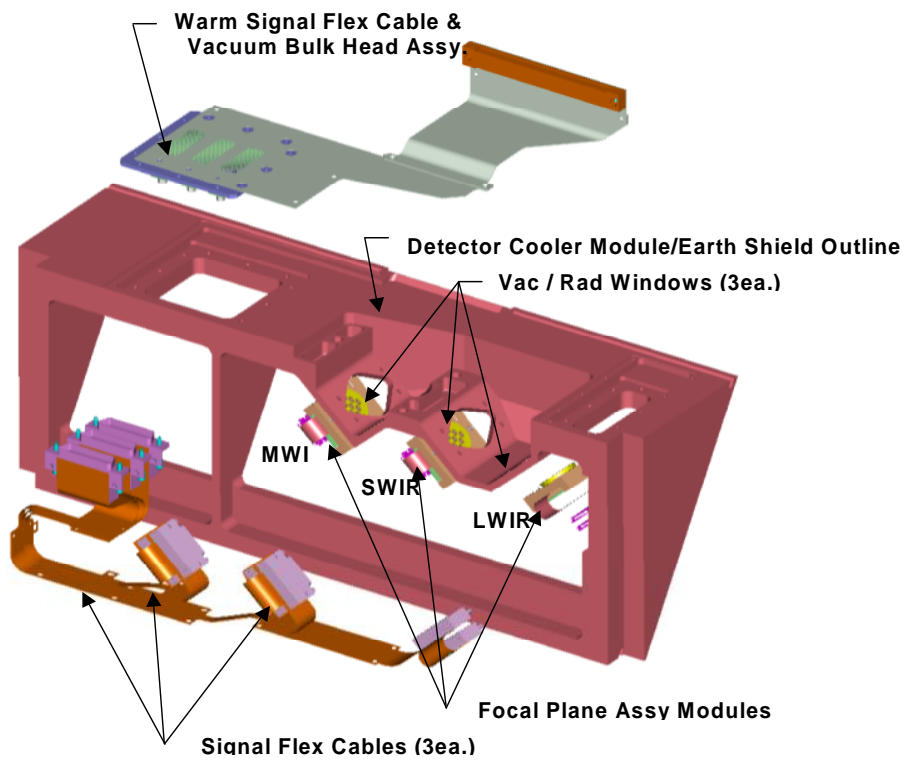

Figure 4. CrIS detector Preamplifier Module (Warm electronics CCAs not shown) 
Quantum efficiency versus wavelength and noise spectral density under dark and illuminated conditions are used to determine the nine photodiodes of each color that are integrated in the FPAA. These detectors are placed in a $3 \times 3$ grid array on the base of the module with a placement accuracy of $+/-2 \mu \mathrm{m}$ from FOV to FOV. Placement of the photodiodes into the sapphire carrier is a critical step in the assembly of the FPAA. Careful procedures are followed to prevent degradation in performance through the FPAA mounting and assembly sequence. A picture of an assembled FPAA is shown in figure 5. Since the photodiodes are backside illuminated, the top metal pad that connects the p-type implants that form a single $850 \mu \mathrm{m}$ diameter lateral collection detector is seen in the picture. Also seen are the discrete components (JFETs, resistors etc.) that constitute the preamplifier module.

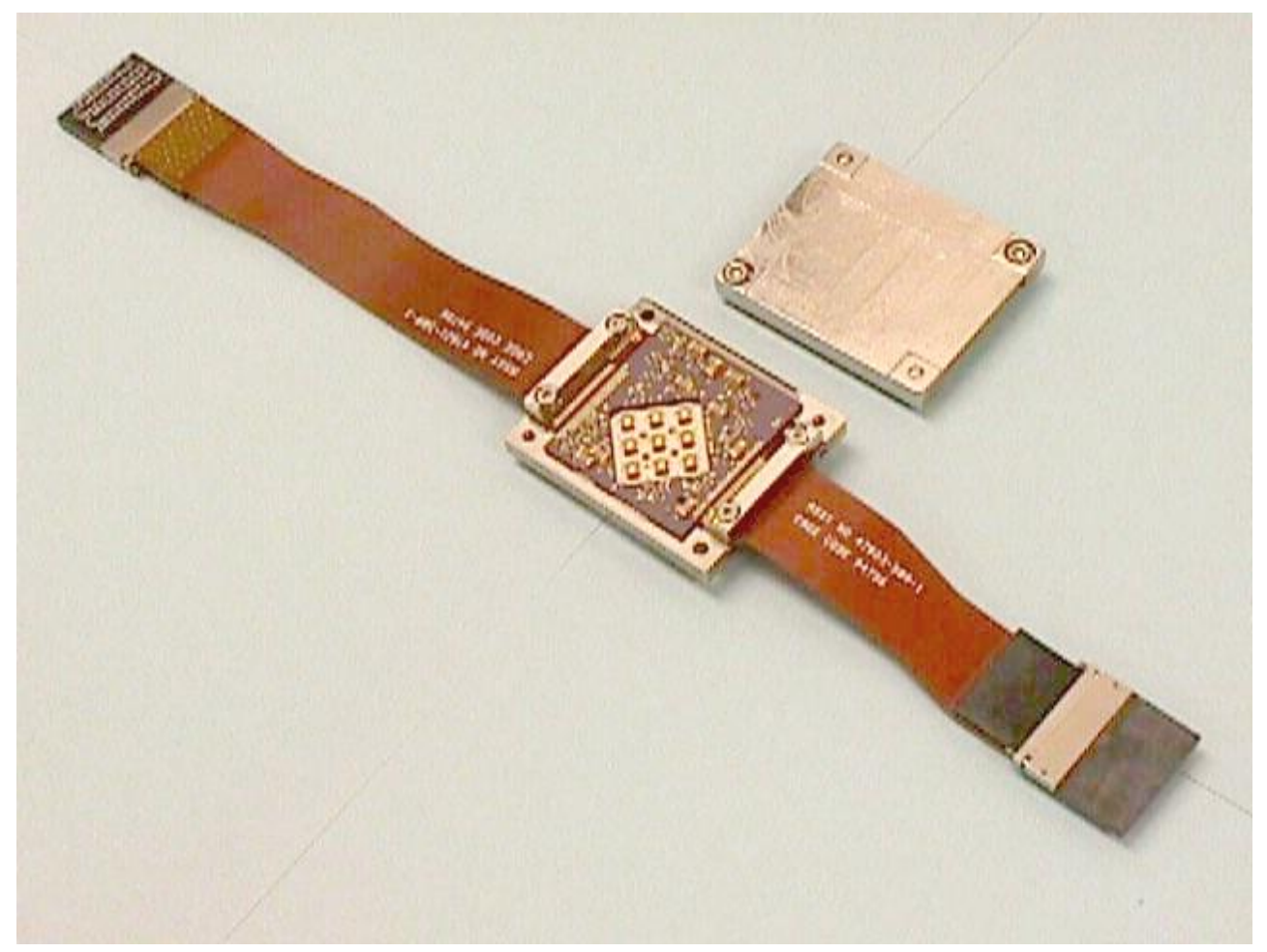

Figure 5. Assembled CrIS LWIR FPAA module

\subsection{Detector \& FPA Performance}

\subsection{GOES-ABI}

An operable detector element is defined as a detector that meets all six different requirements. These six requirements include: linearity, gain stability, long term FPA output stability, output voltage versus bias voltage uniformity, quantum efficiency (QE), and noise equivalent irradiance (NEI). The requirement on is that $100 \%$ of the elements in each linear array spectral channel meet all operability requirements. In order to achieve the stringent operability criteria on every array channel, a detector select capability was designed into each ROIC, where there are 3 redundant columns of detectors per row for the visible bands and 6 redundant columns of detectors per row for the IR bands. The ROIC has a digital switching network and on-board ROIC memory where the optimal detector selection map is loaded onto each FPA via a serial word and one detector per row is read out during normal operation. The remaining redundant columns are switched out. This approach allows the user to select the best detector based on screen test results to maximize performance of the instrument. The detector selection map can be reprogrammed at any time including while on orbit. In addition to column redundancy there are redundant linear arrays per color channel, with each side going to two fully 
independent sets of cryogenic cables, warm cables and two sets of Sensor Unit Electronics (SUE). This Side A/B redundancy allows the user to switch over to the independent redundant side should a channel ever fail while on orbit.

The benefit of the detector select approach with a stringent operability requirement can be seen in the example of a low operability $1230 \mathrm{ch} \mathrm{HgCdTe}$ array, SN8105, which has a $14.2 \mu \mathrm{m}$ cutoff wavelength, Figure 6 . That array consists of 408 rows with 6 redundant columns. The poor performance array is such that it would be a throwaway array under normal circumstances. However, it serves as a good illustration of the best detector selection approach to provide a $100 \%$ operability linear array from a low operability array. The FM1 $1230 \mathrm{ch}$ array side 1 had a full array operability of 73.04\% to all 6 operability requirements. After selection, $100 \%$ row operability is achieved. The $138 \mathrm{ch}(1.38 \mu \mathrm{m}$ spectral band center) array, a $372 \times 6$ array with a cutoff wavelength of $2.5 \mu \mathrm{m}$ had excellent full array operability (99.42\%); after selection it also had $100 \%$ row operability. DRS' array yield was much higher because of the detector selection capability. There is no number of $1230 \mathrm{ch}$ arrays without detector selection capability that would have yielded $100 \%$ operability on both sides. Clearly DRS' approach to use a detector select capability is critical to building perfect arrays meeting very stringent operability requirements.
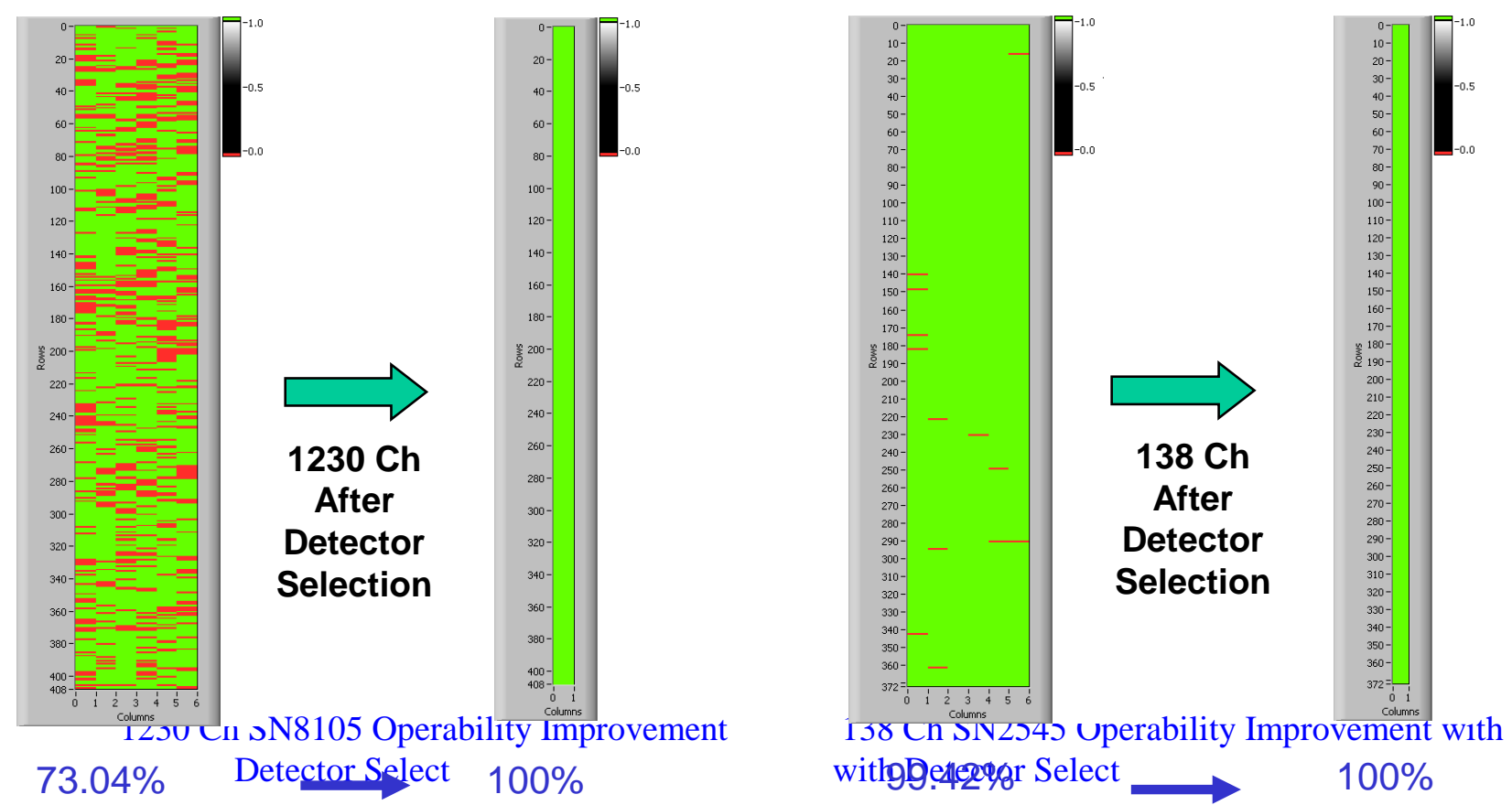

Figure 6. Detector Select allows for $100 \%$ row operability to stressing set of operability requirements (QE, NEI, Linearity, Gain Stability, Long Term Stability, QE vs. bias uniformity)

\subsubsection{Readout Integrated Circuit (ROIC) Architecture}

All the ROIC designs from visible to LWIR use a similar Capacitive Transimpedance Amplifier (CTIA) unit cell amplifier to provide superior linearity and excellent signal injection with both high and low impedance detectors. An example of the ROIC design is the MWIR ROIC shown in figure 7. All the designs also employ detector select circuitry that connects 1 of 6 detectors for the IR channels and 1 of 3 detectors for the visible channels to the unit cell. The redundant detectors that are not selected are automatically tied to the guard bias, which guarantees all the detectors are biased to the same potential whether or not they are attached to the unit cell amplifier. A 3 bit serial word loads the memory cells for each row of the array. This selection map can be overwritten or updated on orbit as necessary. Where a common ROIC is used for multiple FPA channels, the on-ROIC digitally selectable gain setting is optimized for each channel's dynamic range. Correlated Double Sampling (CDS) filtering helps reduce noise at the ROIC output. 


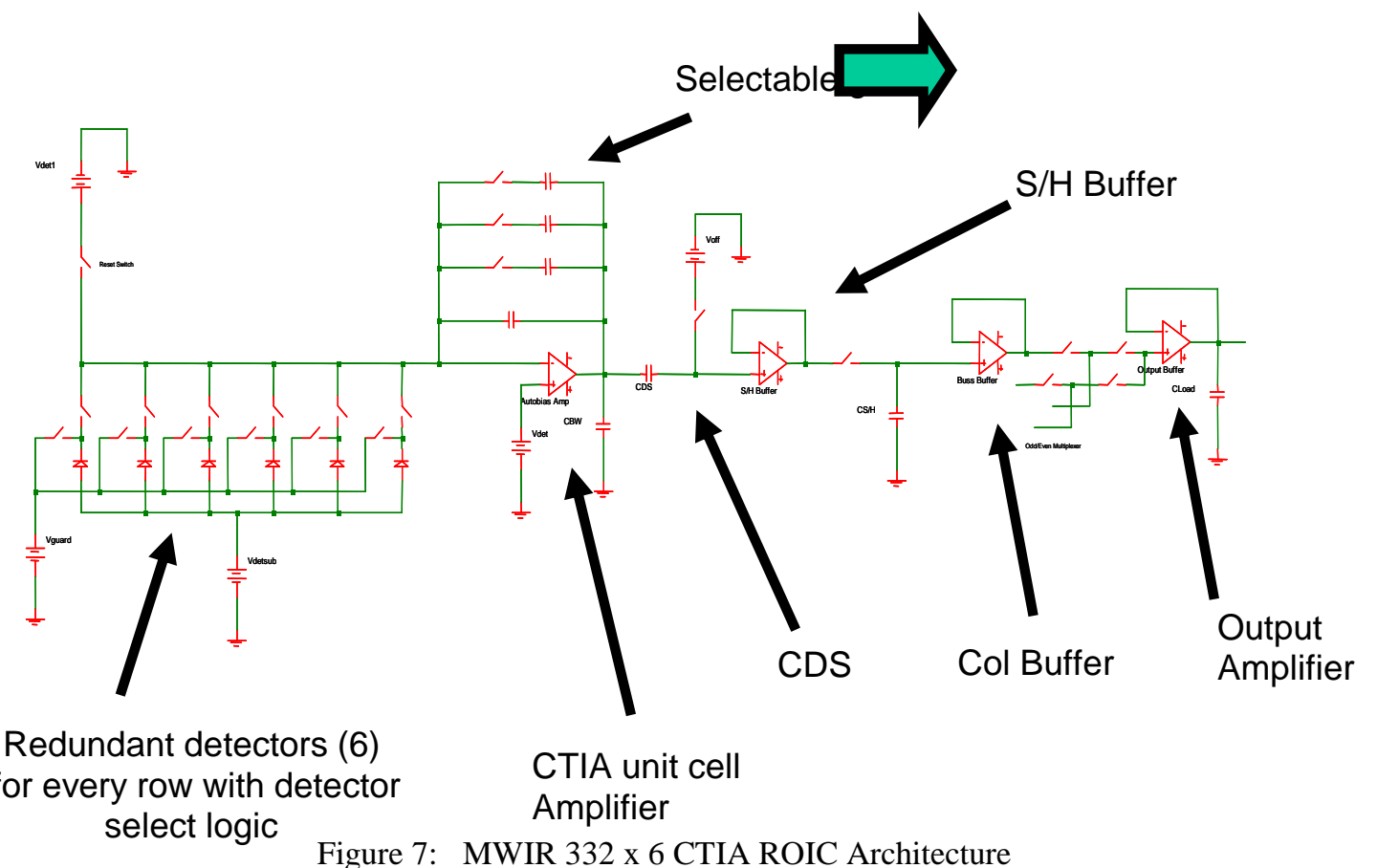

\subsubsection{QE/NEI/Linearity/Gain Stability}

Radiometric testing is performed using an extended source blackbody for the MWIR \& LWIR channels and an integrating sphere for the VNIR channels. Every channel on each module is tested for QE and NEI and compared to the spec. Linearity and gain stability are also tested for every FPA. Test software calculates performance and determines pass/fail to each of the specs and generates a composite operability map. An example of the $1330 \mathrm{ch}$ NEI performance data for all 6 columns on side 1 and with the final selection map is shown in Figure 8. Detectors that had high noise or were on the saturation rail were plotted with an NEI of 1E14 for display purposes on the 6 column plot in Figure 8. Side 2 also has 100\% operability. QE for both redundant sides for the $6.95 \mu \mathrm{m}$ ch array on MWIR FM1 is shown in Figure 9. $100 \%$ of the rows meet the QE and the other 5 spec requirements on both sides.

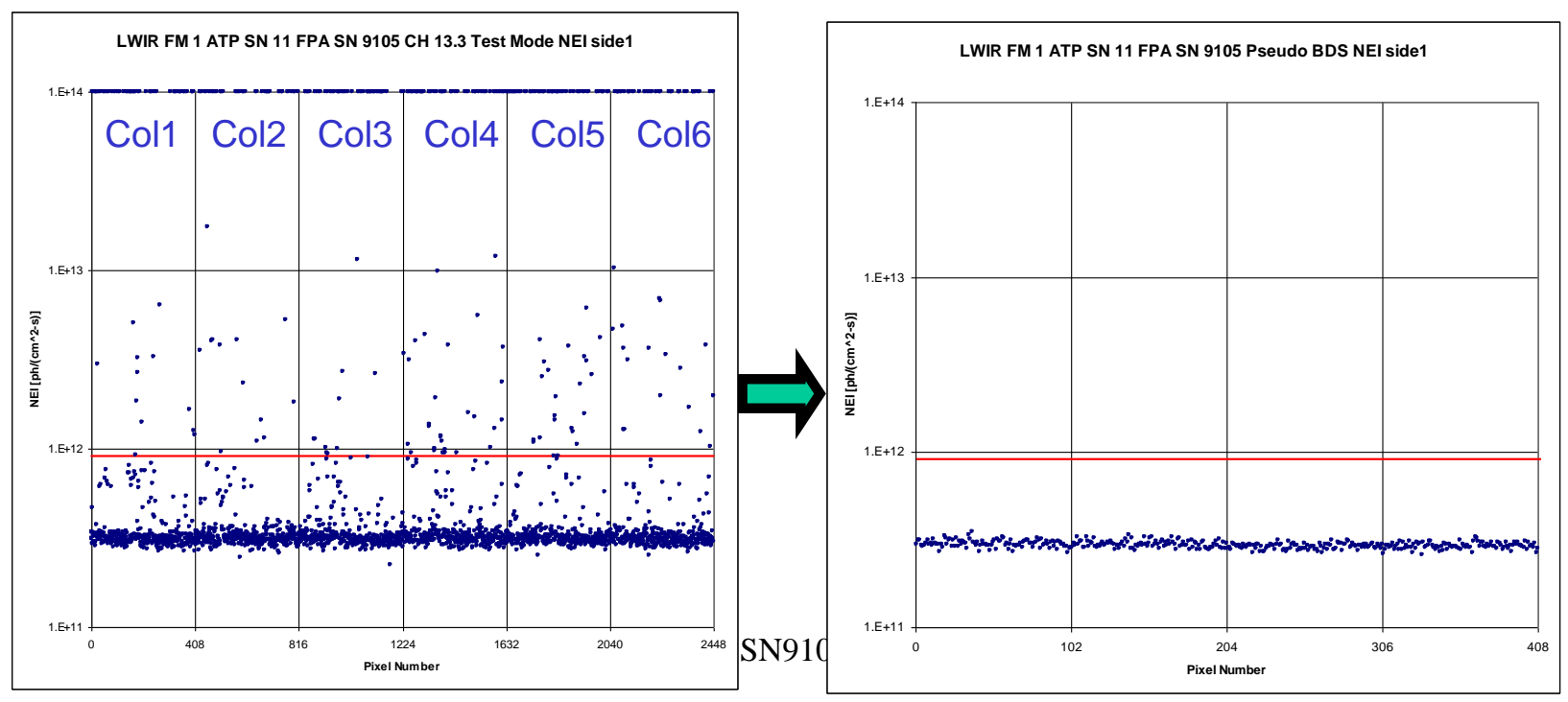



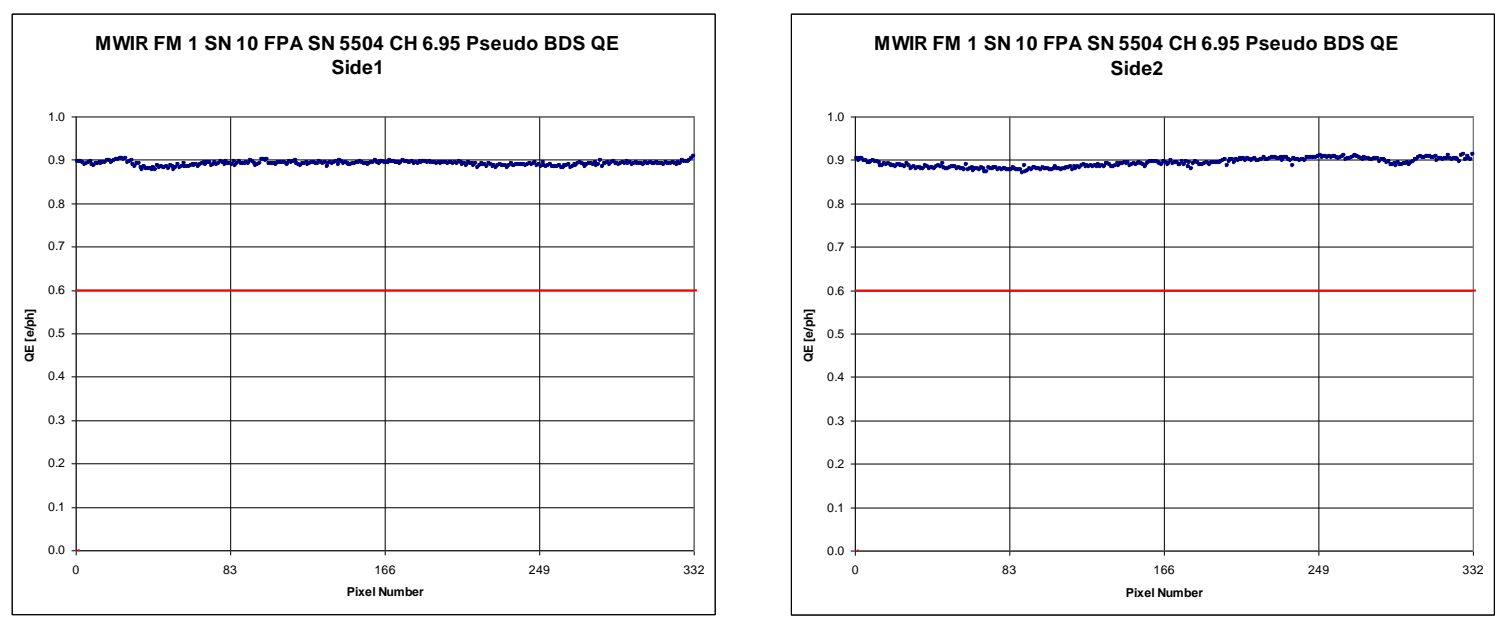

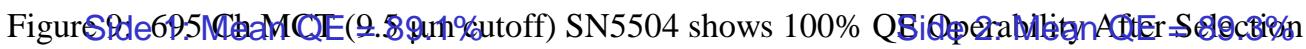
5.1.3 Long Time Series(LTS) Data Capture

$\sigma /$ mean $=1.1 \%$

Scanning array sensors are known to have image striping artifacts due to detector element drift (1/f noise or other forms of excess low frequency noise). The $\mathrm{ABI}$ instrument has an image quality requirement that minimizes the amount of image striping that is permissible. On orbit, the $\mathrm{ABI}$ instrument performs an offset calibration (dark space look) every 30 seconds and a gain correction (cal reference look) every 15 minutes. To insure good image quality of the ABI FPMs, DRS performs Long Time Series testing by capturing successive frames over a $60 \mathrm{sec}$ time interval and analyzing the data for drift for every FPA channel. Over successive time intervals $(512,1024,2048,4096,8192,16,384,32,768$ frames, etc) covering up to 1 minute of data, if a detector's noise is $>20 \%$ of the median array noise or the $>$ NEI, whichever is greater, that detector is rejected. Detectors with minimal low frequency noise will remain stable throughout the 60 seconds. If minimal low frequency noise is present and the noise is white, the noise distribution for the array will tighten up with increasing number of frames. This improvement in noise uniformity is evident in the 1035 ch long time series noise data shown in Figure 10. The mean NEI is unchanged at $2.01 \mathrm{E} 11 \mathrm{ph} / \mathrm{cm}^{2} / \mathrm{sec}$ with increasing number of frames, but the noise distribution tightens up from $\sigma /$ mean $=3.5 \%$ for 512 frames, to $1.89 \%$ for 2,048 frames, and $1.04 \%$ for 32,768 frames.

In addition to the LTS noise requirement there is a gain stability requirement on every operable detector element that states that the gain (i.e. QE) cannot change by more than $+/-0.12 \%$ over a 15 minute time interval for the MWIR and LWIR channels and $+/-0.1 \%$ for the VNIR channels. These requirements along with a linearity requirement of $0.5 \%$ ensure good image quality with minimal image striping for the ABI instrument even when viewing very low contrast scenes.

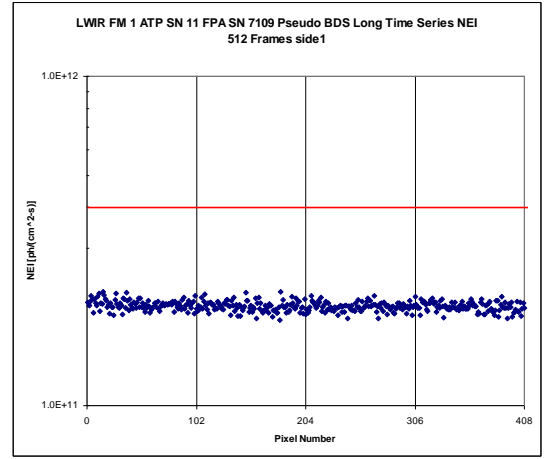

512 Frames NEI Mean $=2.01 \mathrm{E} 11 \mathrm{ph} / \mathrm{cm}^{2} / \mathrm{sec}$ Sigma $/$ mean $=3.50 \%$

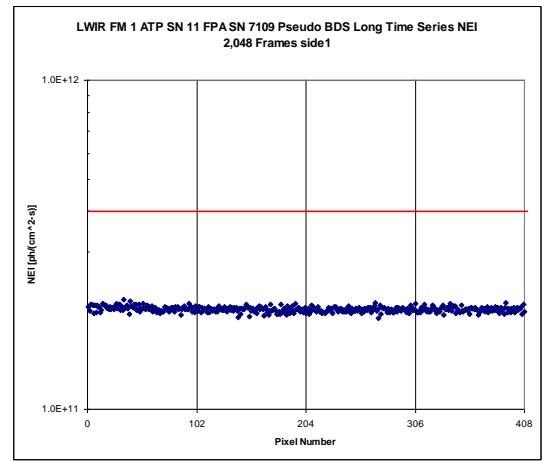

2,048 Frames NEI Mean $=2.01 \mathrm{E} 11 \mathrm{ph} / \mathrm{cm}^{2} / \mathrm{sec}$ Sigma $/$ mean $=1.89 \%$

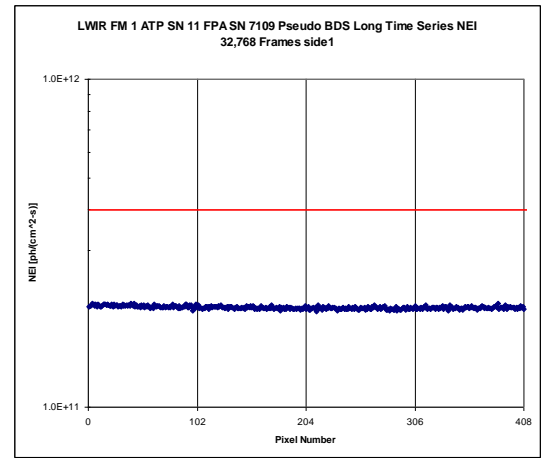

32,768 Frames NEI Mean $=2.01 \mathrm{E} 11 \mathrm{ph} / \mathrm{cm}^{2} / \mathrm{sec}$ Sigma $/$ mean $=1.04 \%$ 
Figure 10: 1035 Ch SN7109 Array NEI Distribution Tightens up with Increasing

Number of Frames

\subsubsection{MTF/Crosstalk/Blooming}

Every array type used on ABI was qualification tested for MTF and crosstalk. This optical testing was done on a sample of representative detectors from each part. Either a HeNe laser $(633 \mathrm{~nm})$ or a $1.55 \mu \mathrm{m}$ diode laser, depending on the array type, was used as a source and imaged with a macro lens on to the array. Using an automated precision stepper motor a 2 D fine scan and a coarse raster scan of the spot were performed to simulate a knife edge response (line spread function) for MTF. A MATLAB program interpolated the fine and coarse scan data and calculated an FFT of the line spread function data to generate an MTF curve for the detector under test

Figure 11 shows the photo response from a 2-D fine spot scan taken on the 138/225 ch prototype design and Flight Design. The via on the HDVIP® design is the dip in photo response at the center of the detector response profile. It is inconsequential to detector QE or MTF. What is evident when looking at the spot scans is the "soft" edges and response lobes in the corners of the prototype design. The softness of the edge response and corner lobes is due to collection of electrons from outside the intended active area.By adding the "picture frame" shaped surface implants, the photoresponse profile of the detector edges sharpened up dramatically. Any electrons diffusing in the p-type MCT are collected by the surface implant rather than making their way to a neighboring detector element. The addition of the surface implant provided a significant improvement to crosstalk and MTF performance for flight. Figure 12 shows the E-W and N-S MTF performance relative to the ABI spec for both designs.

\section{PTM}

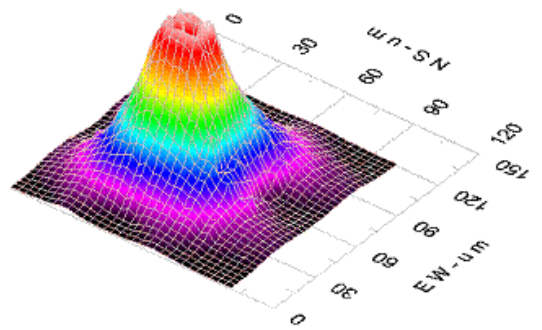

Figure detector edge resp
mparison 633nm MTF
Airy Disk Removed

design in

Flight

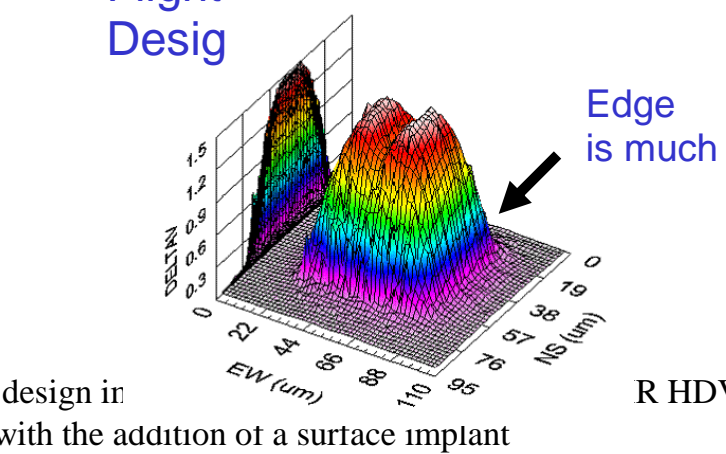




\subsection{CrIS}

\subsubsection{Single photodiode I-V, Quantum Efficiency, Spectral Response and Noise}

Detectors fabricated on a wafer are wirebonded in a carrier and dark I-V measurements at the $98 \mathrm{~K}$ for SWIR and MWIR and $81 \mathrm{~K}$ for LWIR operating temperatures. The magnitude of the current and shape of the I-V characteristics serves as a screen to pick detectors that will be inserted into Leadless Chip Carriers (LCCs). Each candidate detector selected from the wafer dark I-V measurement that is mounted into an LCC is measured in the dark and multiple flux conditions for I-V characteristics, noise under dark and illuminated conditions, spectral response and quantum efficiency (QE) performance at the specified operating temperature. Noise is measured at the nominal flux at which the photodiode will operate within the CrIS instrument.

A commercial Fourier transform infrared spectrometer is used to obtain the spectral response at $81 \mathrm{~K}$ for all the LWIR photodiodes. All measurements are made at the temperature and bias at which the photodiodes will operate within the CrIS instrument. For the LWIR photodiodes, absolute QE is measured at $\lambda=10.6 \mu \mathrm{m}$ using a narrow band filter. Narrow band filters centered at $\lambda=7.4 \mu \mathrm{m}$ and $\lambda=4.0 \mu \mathrm{m}$ are used for the MWIR and SWIR photodiodes QE measurements. The QE and spectral cut-off are traceable to NIST. The quantum efficiency using a narrow band filter is combined with the spectral response curve to obtain the QE versus wavelength curve as displayed in Figure 13 for a representative LWIR photodiode. QE as a function of wavelength is a principal specification that has to be met for a photodiode to be utilized in the CrIS instrument. The specification QE is also displayed in Figure 13 as a dashed red line. As can be seen from the figure the QE is high. Fringes seen in the data are a result of etalon effects in the anti-reflection coating and the detector. Modeling of QE vs wavelength have been described previously. ${ }^{14}$

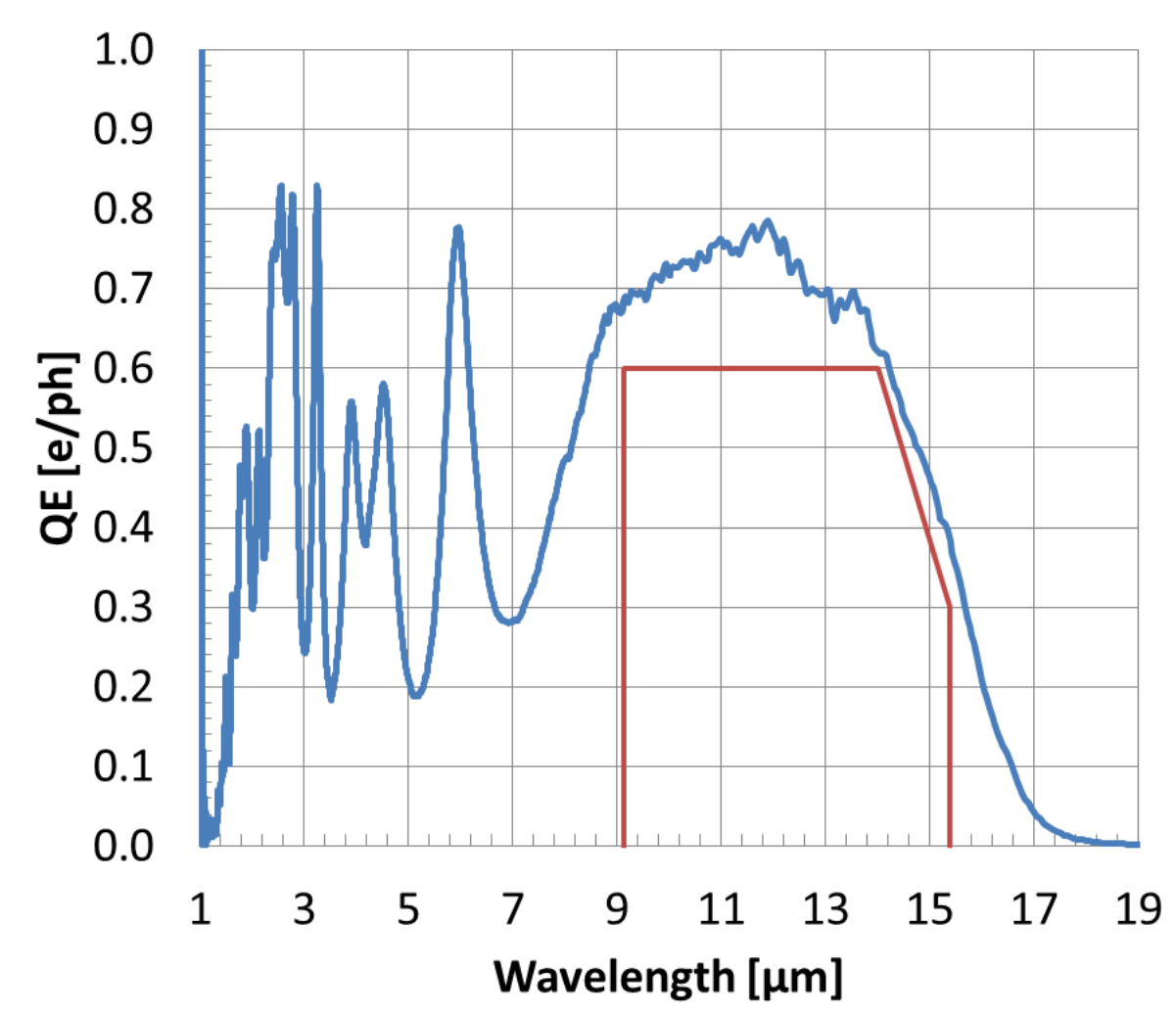

\section{[5.4 $\mu \mathrm{m}]$ photodiode}

ature, i.e. LWIR are measured at jise spectral density curves in the kes are reflective of pickup from down to $\sim 500 \mathrm{~Hz}$. Figure $14 \mathrm{~b}$ is e from Figure 14a. The line at 14 ation with margin. These are the photodiodes that are selected for placement in the FPAA. Similar measurements and calculations are made for the MWIR photodiodes. SWIR photodiodes at $98 \mathrm{~K}$ have calculated white noise values in the low $10^{-15} \mathrm{~A} / \mathrm{Hz}^{1 / 2}$ range. This noise level is impossible to measure consistently and accurately using the noise measurement station and commercial amplifiers 
such as the Ithaco 1211 that are run at room temperature. and $\Phi=1.8 \times 10^{15} \mathrm{ph} / \mathrm{cm}^{2} / \mathrm{s}$ respectively. Similar procedures are followed for the selection of MWIR and SWIR photodiodes prior to their selection for placement into FPAAs.
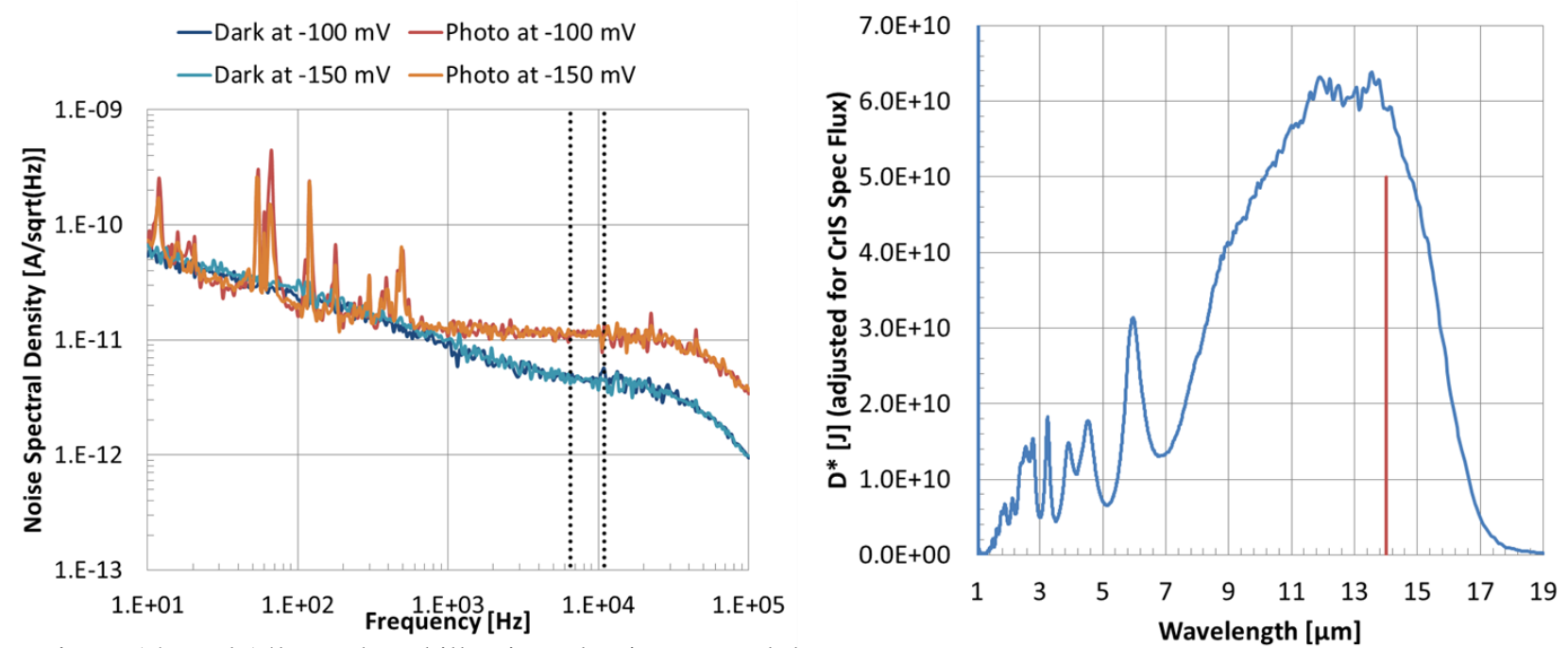

Figure 14a and 14b. Dark and illuminated noise spectral d

\subsubsection{LWIR FPAA Data}

Nine candidate LWIR photodiodes have been mounted on the sapphire base and incorporated into the LWIR FPAA along with the preamplifier, cables etc. as shown in figure 5. The LWIR FPAA is currently being assembled and will be completed. Testing will be completed by end of March and data will be added to the paper when it is collected. The detectors will be cooled to $81 \mathrm{~K}$ and the photodiodes held at $100 \mathrm{mV}$ reverse bias during subsequent responsivity and noise measurements. The reason for holding the photodiodes in reverse bias is two-fold. The impedance of large $\lambda_{c}(98 \mathrm{~K})$ $\sim 9 \mu \mathrm{m}$, and $\lambda_{\mathrm{c}}(81 \mathrm{~K}) \sim 15.4 \mu \mathrm{m}$ photodiodes is quite low at zero bias. A pre-amplifier interfacing with a low impedance detector results in high noise in the pre-amplifier. Also, the injection efficiency is depressed, rendering it impossible to extract the photocurrent efficiently. Consequently, the external quantum efficiency is low. Operating the detector in reverse bias can increase the detector dynamic impedance by two orders of magnitude, resulting in the external quantum efficiency rising to the value of the internal quantum efficiency.

Noise measurements at the nominal operating flux of $\Phi=3.5 \times 10^{17}$ photons $\cdot \mathrm{cm}^{-2} \cdot \mathrm{s}^{-1}$ are made for all the photodiodes in the FPAA. These flux values are achieved using an Electro-Optical Industries (EOI) Black Body mounted external to the dewar. The dewar flux is calibrated using a detector with known QE. For the LWIR FPAA, the electrical band of interest is $6.5-10.95 \mathrm{kHz}$. To obtain maximum performance, the photodiode noise needs to be photon noise dominated within the frequency band of interest. The gain of the pre-amplifier is designed to be maintained constant within the frequency band of interest. There is a one-to-one correspondence between response at a particular wavelength $\lambda_{\mathrm{t}}$ and noise at frequency $\mathrm{f}_{\mathrm{i}}$. To calculate $\mathrm{D}^{*}$ at any wavelength, the quantum efficiency at any wavelength $\eta(\lambda)$, is ratioed to the noise corresponding to that particular wavelength. The other parameters listed in the $\mathrm{D}^{*}$ equation 1 below are then input to calculate $\mathrm{D}^{*}$ as a function of wavelength, $D^{*}(\lambda)$. Figure 15 is a plot of $\mathrm{D}^{*}$ versus $\lambda$ for all the nine photodiodes in a previous LWIR FPAA which will be updated as the LWIR FPAA data is collected.

$$
\boldsymbol{D} *(\lambda)=\frac{\boldsymbol{q} \lambda \boldsymbol{A}_{\mathrm{det}}{ }^{\frac{1}{2}} \eta(\lambda)}{\boldsymbol{h} \boldsymbol{c} \boldsymbol{i}_{\boldsymbol{n}}(\lambda)}
$$




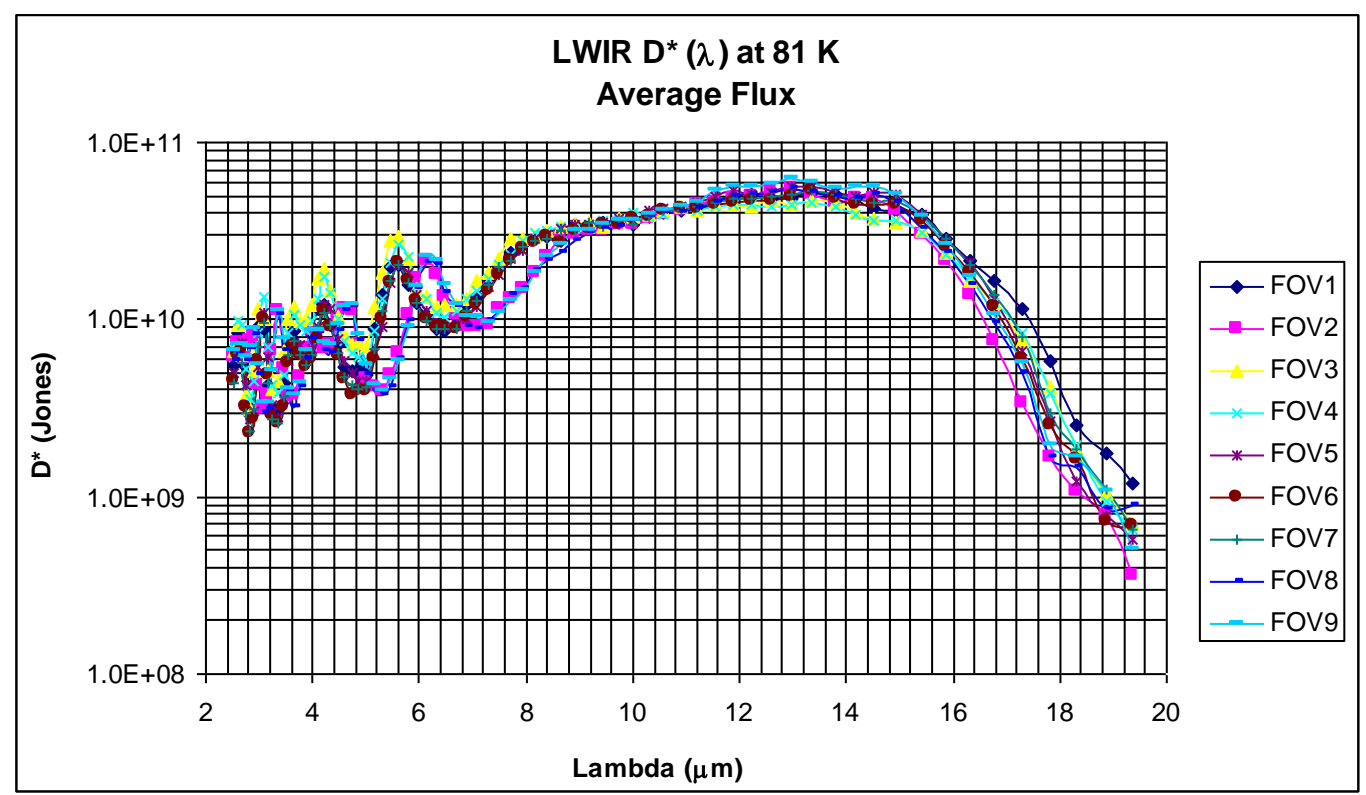

Figure 15. LWIR Spectral D* at $81 \mathrm{~K}$ and nominal flux $\Phi=3.5 \times 10^{17}$ photons $\cdot \mathrm{cm}^{-2} \cdot \mathrm{s}^{-1}$

\subsection{MWIR FPAA Data}

The MWIR FPAA is cooled to $98 \mathrm{~K}$ and the photodiodes are also held at $100 \mathrm{mV}$ reverse bias as in the LWIR FPAA case. Noise measurements are made at the nominal $\Phi=6.2 \times 10^{16}$ photons $\cdot \mathrm{cm}^{-2} \cdot \mathrm{s}^{-1}$. The electrical band of interest is 12.1-17.5 kHz, corresponding to wavelengths $\lambda=8.26 \mu \mathrm{m}$ down to $\lambda=5.71 \mu \mathrm{m}$. Spectral QE and $\mathrm{D}^{*}$ as a function of wavelength is plotted in Figure 16. The average $\mathrm{D}^{*}$ at $8.26 \mu \mathrm{m}$ was $9.57 \times 10^{10}+/-4.16 \times 10^{9} \mathrm{~cm}-\mathrm{Hz}^{1 / 2} / \mathrm{W}$, exceeding the specification $\mathrm{D}^{*}=7.5 \times 10^{10} \mathrm{~cm}-\mathrm{Hz}^{1 / 2} / \mathrm{W}$ by $27.6 \%$.
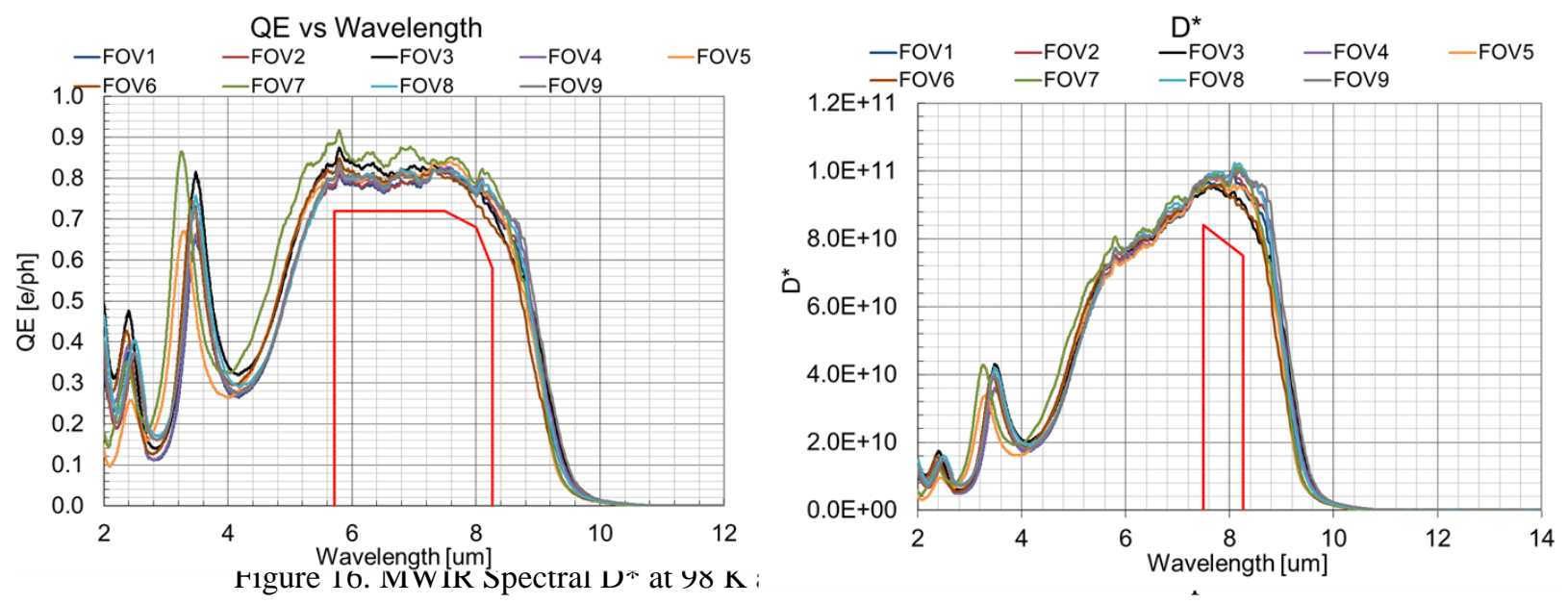


\subsection{SWIR FPAA Data}

The SWIR FPAA is cooled to $98 \mathrm{~K}$ and the detectors are held at $60 \mathrm{mV}$ reverse bias. Noise measurements are made at the nominal $\Phi=1.8 \times 10^{15}$ photons $\cdot \mathrm{cm}^{-2} \cdot \mathrm{s}^{-1}$. The electrical band of interest is $21.5-25.5 \mathrm{kHz}$, corresponding to wavelengths $\lambda=4.64 \mu \mathrm{m}$ down to $\lambda=3.92 \mu \mathrm{m}$. Spectral $\mathrm{D}^{*}$ as a function of wavelength is plotted in Figure 17. The average $\mathrm{D}^{*}$ at $4.64 \mu \mathrm{m}$ is $3.38 \times 10^{11}+/-1.21 \times 10^{10} \mathrm{~cm}-\mathrm{Hz}^{1 / 2} / \mathrm{W}$, exceeding the specification $\mathrm{D}^{*}=3.0 \times 10^{11} \mathrm{~cm}^{-\mathrm{Hz}^{1 / 2} / \mathrm{W}}$ by $12.6 \%$ and close to the BLIP D* of $4.2 \times 10^{11} \mathrm{~cm}-\mathrm{Hz}^{1 / 2} / \mathrm{W}$. The BLIP $\mathrm{D}^{*}$ is calculated using a $\mathrm{QE}=1$.
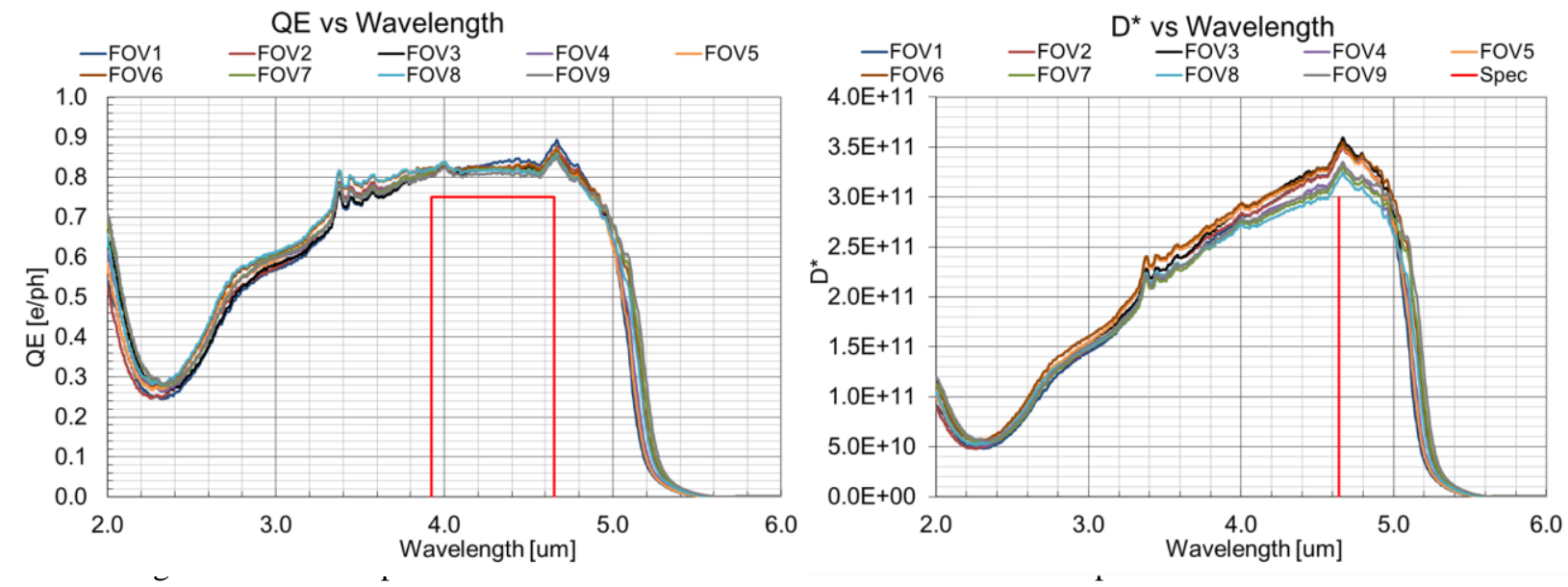

\subsection{SUMMARY}

DRS has successfully designed and manufactured FPM modules for GOES ABI. Detectors for the 16 channels were fabricated using three different technologies. Visible channels detector arrays were fabricated using Si pin diode technology. The VNIR through 961 channel detectors were fabricated in LPE grown $\mathrm{HgCdTe}$ detectors utilizing the HDVIP detector architecture. The LWIR channels HgCdTe were grown by MBE and fabricated using the DLPH detector architecture. The GOES ABI instrument will provide a significant performance improvement over current GOES imagers. DRS has delivered fully compliant Flight Module shipsets (VNIR, MWIR and LWIR) with 100\% detector row operability on all 16 channels to the ITT-Exelis-Harris ABI sensor requirements.

The appropriate bandgap n-type $\mathrm{Hg}_{1-\mathrm{x}} \mathrm{Cd}_{\mathrm{x}} \mathrm{Te}$ was grown on lattice-matched CdZnTe. 850 - $\mu$ m-diameter photodiodes were manufactured using a Lateral Collection Diode (LCD) architecture. Custom pre-amplifiers are separately designed to interface with the large LWIR and MWIR low impedance photodiodes and with SWIR photodiodes at frequencies up to $25.5 \mathrm{kHz}$. Pre-amplifier gain is maintained constant within the electrical band of interest for each color. The LWIR, MWIR and SWIR photodiodes are operated at $81 \mathrm{~K}, 98 \mathrm{~K}$ and $98 \mathrm{~K}$ respectively. Performance goals are $\mathrm{D}^{*}=5.0 \times 10^{10}$ $\mathrm{cm}-\mathrm{Hz}^{1 / 2} / \mathrm{W}$ at $14.0 \mu \mathrm{m}, 7.5 \times 10^{10} \mathrm{~cm}-\mathrm{Hz}^{1 / 2} / \mathrm{W}$ at $8.26 \mu \mathrm{m}$ and $3.0 \times 10^{11} \mathrm{~cm}-\mathrm{Hz}^{1 / 2} / \mathrm{W}$ at $4.64 \mu \mathrm{m}$. Measured mean values for the nine photodiodes in each of the LWIR, MWIR and SWIR FPAAs are $\mathrm{D}^{*}=5.3 \times 10^{10} \mathrm{~cm}-\mathrm{Hz}^{1 / 2} / \mathrm{W}$ at $14.01 \mu \mathrm{m}, 9.6$ $\mathrm{x} 10^{10} \mathrm{~cm}-\mathrm{Hz}^{1 / 2} / \mathrm{W}$ at $8.26 \mu \mathrm{m}$ and $3.1 \times 10^{11} \mathrm{~cm}-\mathrm{Hz}^{1 / 2} / \mathrm{W}$ at $4.64 \mu \mathrm{m}$. These compare favorably with the BLIP calculated at the nominal flux condition are $\mathrm{D}^{*}=8.36 \times 10^{10} \mathrm{~cm} \mathrm{~Hz}^{1 / 2} / \mathrm{W}$ at $14.01 \mu \mathrm{m}, 1.4 \times 10^{11} \mathrm{~cm}-\mathrm{Hz}^{1 / 2} / \mathrm{W}$ at $8.26 \mu \mathrm{m}$ and $3.4 \mathrm{x}$ $10^{11} \mathrm{~cm}-\mathrm{Hz}^{1 / 2} / \mathrm{W}$ at $4.64 \mu \mathrm{m}$.

\subsection{REFERENCES}

1. H.D. Shih, M.A. Kinch, F. Aqariden, P.K. Liao, H.F. Schaake, Appl. Phys. Lett. Vol. 83, 4157(2003).

2. M.A. Kinch, Proc. SPIE meeting, Vol. 4369, pp. 566-578 (Orlando, April 2001).

3. J.M. Arias, S.H. Shin, J.G. Pasko, R.E. DeWames, E.R. Gertner, J. Appl. Phys. 65, 1747 (1989).

4. J.M. Arias, M. Zandian, J.G. Pasko, S.H. Shin, L.O. Bubulac, R.E. DeWames, W.E. Tennant, J. Appl. Phys. 69, 2143 (1991).

5. J. Bajaj, J.M. Arias, M. Zandian, J.G. Pasko, L.J. Kozlowski, R.E. DeWames, W.E. Tennant, J. Electron. Mater. 24, 1067 (1995). 
6. J.M. Arias, J.G. Pasko, M. Zandian, S.H. Shin, G. M. Williams, L.O. Bubulac, R.E. DeWames, W.E. Tennant, Appl. Phys. Lett. 62, 976 (1993).

7. A.I. D'Souza, L.C. Dawson, E.J. Anderson, A.D. Markum, W.E. Tennant, L.O. Bubulac, M. Zandian, J.G. Pasko, W.V. McLevige, D.D. Edwall, J. Electron. Mater. 26, 656 (1997).

8. J.M. Arias, J.G. Pasko, M. Zandian, S.H. Shin, G.M. Williams, L.O. Bubulac, R.E. DeWames, W.E. Tennant, J. Electron. Mater. 22, 1049 (1993).

9. S.H. Shin, J.M. Arias, M. Zandian, J.G. Pasko, L.O. Bubulac, R.E. DeWames, J. Electron. Mater. 22, 1049 (1993).

10. H. Holloway, J. Appl. Phys., 49, 4264 (1978)

11. P.S. Wijewarnasuriya, M. Zandian, D.B. Young, J. Waldrop, D.D. Edwall, W.V. McLevige, J. Arias, A.I. D'Souza, J. Electron. Mater. 28, 649 (1999).

12. S. Masterjohn, A.I. D'Souza, L.C. Dawson, P. Dolan, P.S. Wijewarnasuriya, J. Ehlert, SPIE Proceedings Vol. 4820, pg. 368, International Symposium on Optical Science and Technology, 7 - 11 July 2002, Seattle, WA.

13. A.I. D’Souza, L.C. Dawson, S. Marsh, R. Willis, P.S. Wijewarnasuriya, R.E. DeWames, J.M. Arias, J. Bajaj, G. Hildebrandt, F.E. Moore, SPIE Proc. Vol. 4369, p. 157.

14. A.I. D'Souza, E. Robinson, M.G. Stapelbroek, P.S. Wijewarnasuriya, J. of Electronic Materials, Vol. 40, No. 8, 1657 (2011).

15. A.I. D’Souza, M.G. Stapelbroek, P.N. Dolan, P.S. Wijewarnasuriya, R.E. DeWames, D.S. Smith, J.C. Ehlert, J. of Electronic Materials, 32, 633 (2003).

16. A.I. D'Souza, M.G. Stapelbroek, P.S. Wijewarnasuriya, R.E. DeWames, D.S. Smith, J.C. Ehlert, SPIE Proceedings Vol. 4820, pg. 389, Intl. Sym. on Optical Science and Tech., 7 - 11 July 2002, Seattle, WA. 